\title{
PREVENTION IS BETTER THAN CURE
}

\section{Addressing violent crime in South Africa}

Sibusiso Masuku, Institute for Security Studies

sibusiso@iss.co.za

South Africa's high levels of violent crime have a significant effect on people's lives. A review of the trends and risk factors associated with violent crime begs the question about who should be leading the effort to prevent violence? The South African Police Service currently has this responsibility - but is this appropriate? And which other departments should be playing a greater role?

$\mathrm{T}$ he South African Police Service (SAPS) performance report for the financial year 2001/2002 indicates a decrease and stabilisation in a number of serious crimes recorded by the police. Of paramount importance is the stabilisation and decrease in some violent crimes recorded by the SAPS. ${ }^{1}$ This should be a relief for crime-fearing South Africans. It is important to note, however, that these crimes are stabilising at a high level. South African crime rates, and, more specifically, violent crime, remain unacceptably high. For example, the report shows that over 21,400 cases of murder, nearly 540,000 cases of rape and over 116,700 cases of serious robbery were recorded in 2000/01. It is this high level of violent crime that sets South Africa apart from other crime-ridden societies.

\section{Impact of high levels of violence}

Victim surveys generally show that violent crimes are of major concern to the public. ${ }^{2}$ The physical and emotional impact of these crimes is devastating for victims, their families and communities. The occurrence of these crimes, coupled with the fact that this subject dominates news headlines, heightens public fear of crime. This creates misery for individuals and destabilises communities. ${ }^{3}$

Police are constantly (and often unfairly) criticised by the public and the media for failing to deal effectively with crime in general, and violent crime in particular. O ne effect of this pressure can be seen in the police's use of targeted, high-visibility search and seizure operations to 'stabilise' the situation. Hence the ongoing police strategy publicly known as 'O peration Crackdown' that was initiated in 2000. This strategy is largely based on high-density operations in selected high crime areas, focusing mainly on roadblocks, searches and raids.

There is nothing wrong with this strategy per se, but it is important to realise that such measures usually have short-term benefits and are difficult and costly to sustain in the long-term. Moreover, responses of this kind rarely have an impact on the factors behind violent crime. Key to the prevention of violent crimes is the understanding of various individual, social and environmental risk factors associated with these crimes. O nly when various forms of violent crime and the risk factors are separated and carefully analysed, will meaningful long-term solutions be produced.

This article considers the trends of violent crime as recorded by the SAPS from M arch 1994 to M arch 2002, and some of the risk factors associated with these crimes. (Statistics for the financial years rather than the period January to D ecember of each year are used because the latest SAPS figures are based on financial years.) 


\section{Trends in violent crime}

Violent crime as categorised in the official SAPS statistics includes various offences that differ from each other in terms of type and seriousness. For the purposes of this article however, individual crime types have been divided into two categories.

- interpersonal violent crime: murder, attempted murder, serious and common assaults, and rape;

- violent property crime: these include all categories of robbery, i.e. robbery with aggravating circumstances (armed robbery, car hijacking etc.) and common robbery.

Levels of violent crime in South African are high. A bout 839,639 violent crimes were recorded by the police between March 2001 and March 2002. Both categories of violent crime, that is, interpersonal violent crimes and violent property crimes have been increasing since 1994, although in 2001/02 the extent of the increase was less than in previous years (Figure 1).

\section{Interpersonal violent crime}

Murder and attempted murder: Reported and recorded cases of murder are a key indicator of trends in respect of violent crime more generally. What constitutes murder is rarely disputed, and it is generally well reported compared to other interpersonal crimes. Since 1994/95 the number of murders has slowly been declining, with a slight increase in 1998/99, after which levels dropped again to 2001/02 (Figure 2).

This is the only violent crime type recorded by the SAPS that clearly shows a declining trend.

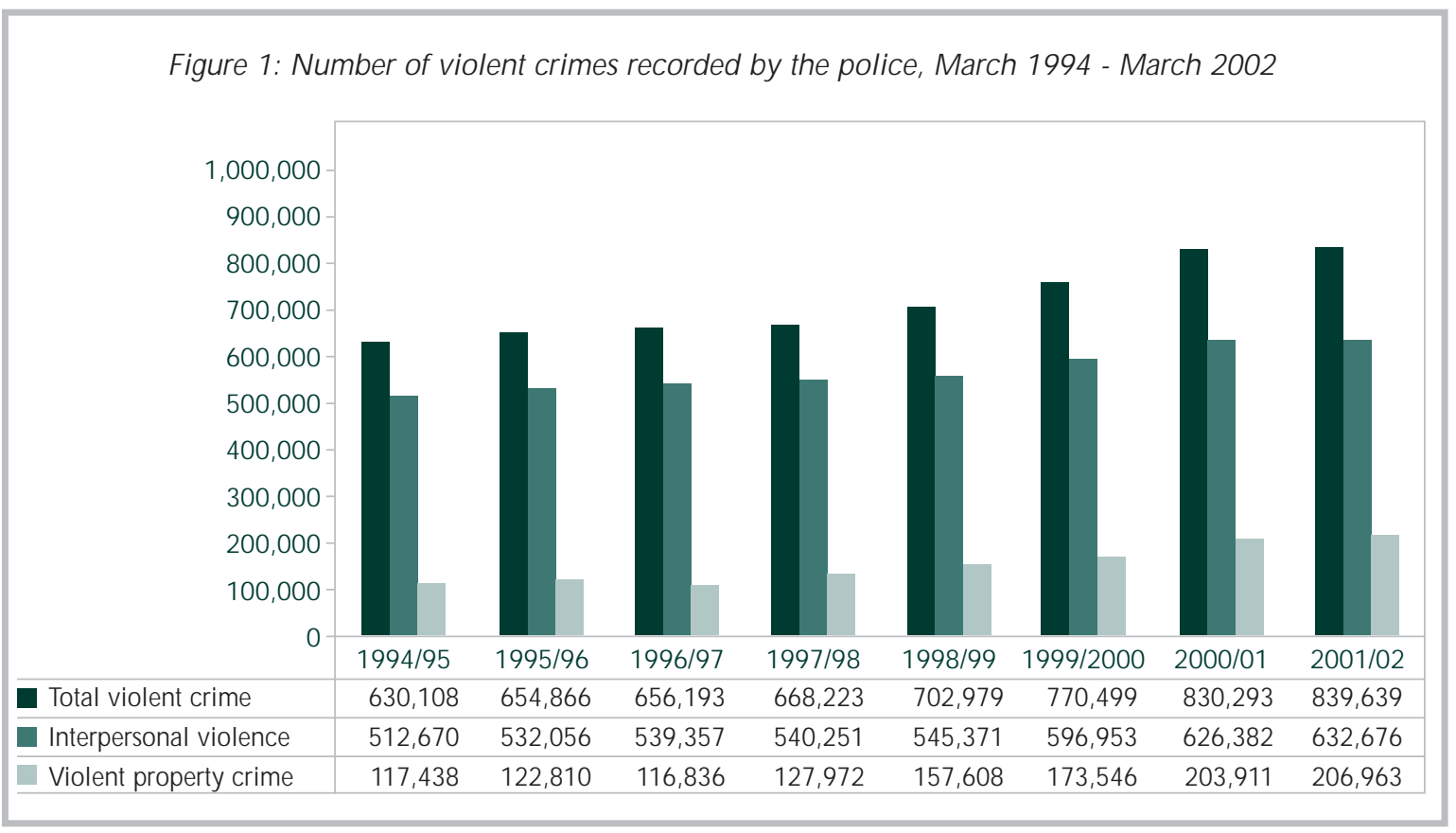

Figure 2: Trends for murder and attempted murder recorded by the police, March 1994 - March 2002

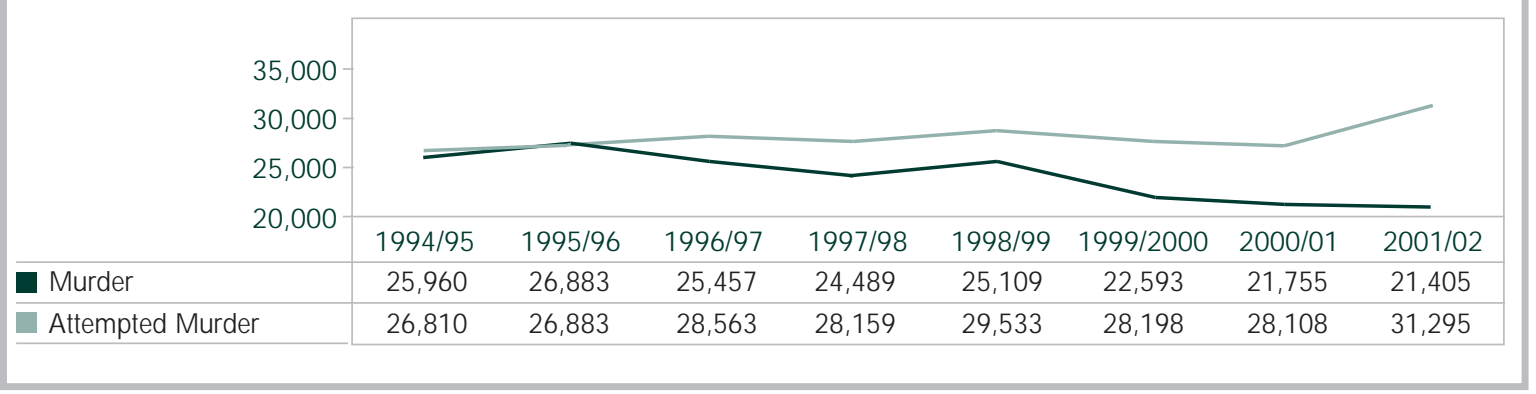




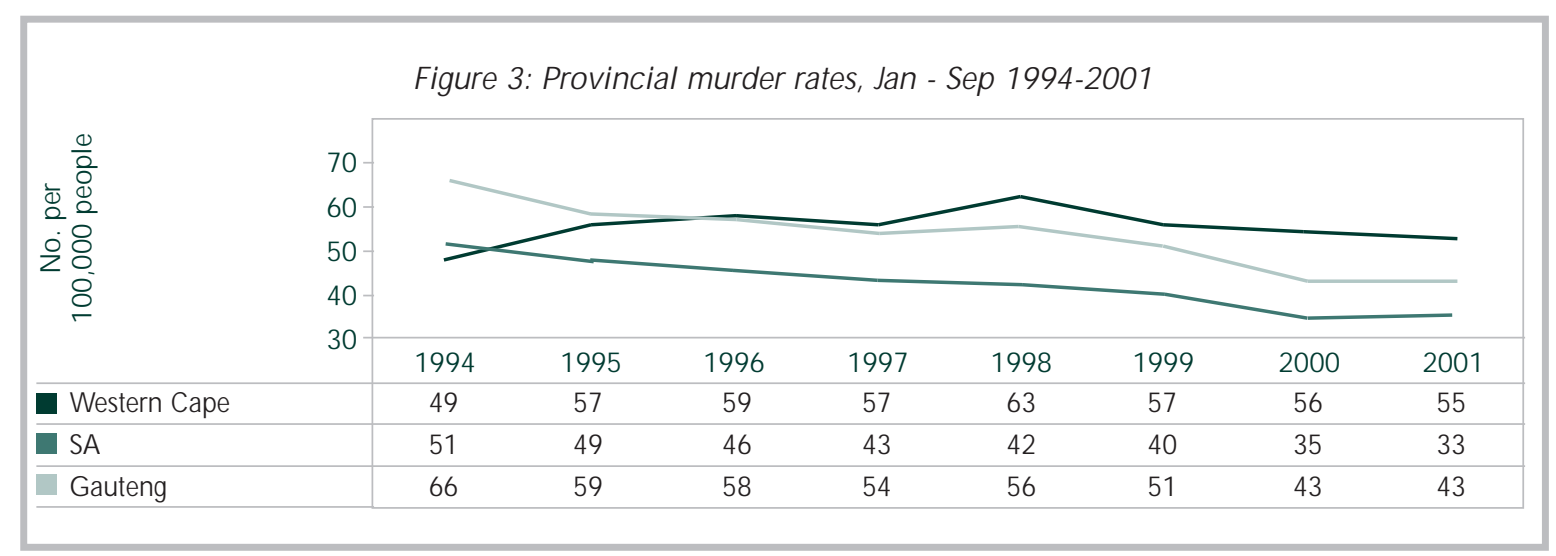

Figure 4: Trends for serious and common assaults recorded by the police, March 1994 - March 2002

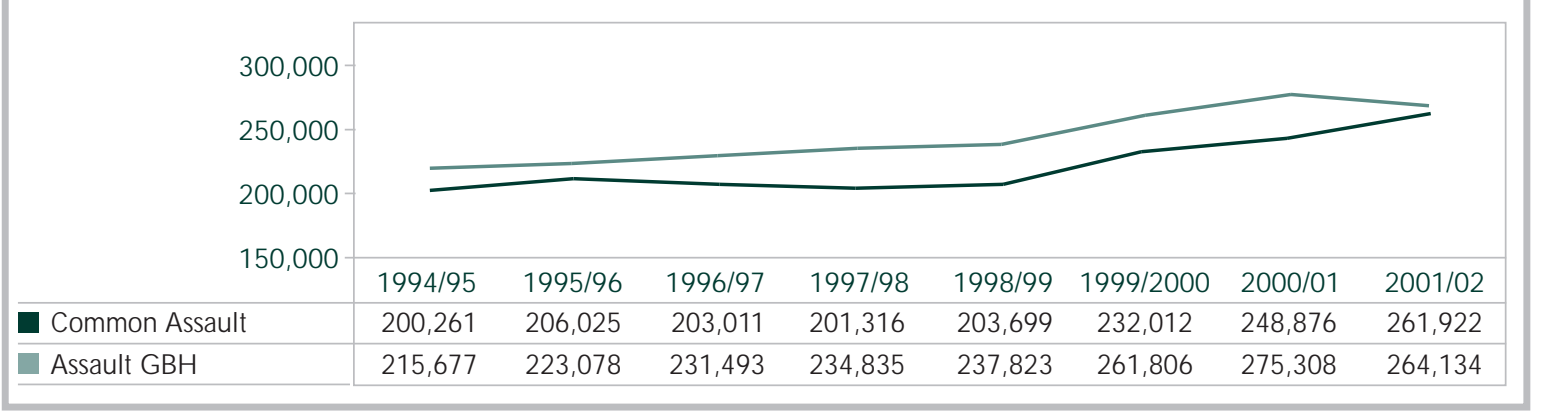

In contrast to the declining number of murders, attempted murder has slowly been rising over the period under discussion, with a big increase in 2001/02 (Figure 2). Considering that murder and attempted murder are similar types of crime, it is unusual that one is decreasing and the other is on the increase.

The drop in murders between 1994/95 and 1996/97 can possibly be attributed to the decrease in political violence, particularly in Gauteng and KwaZulu-N atal. This explanation is, however, limited, since it does not account for the continuous drop in murder rates after 1996, or for the increase in murders in the Western Cape (Figure 3). Given the seriousness of this offence, and the fact that trends for other violent crimes are not similar to that of murder, there is a need for a thorough investigation into these trends and the continuous monitoring of future developments.

Serious and common assault: The recorded number of serious assaults (also referred to as assault with intent to do grievous bodily harm) gradually increased from 1994/95 with a slightly larger increase in 1999/2000, followed by a small decline of four per cent in 2001/02. Common assaults, by comparison, stabilised between 1995/96 and $1998 / 99$, and rapidly increased from $1999 / 2000$ to 2001/02 (Figure 4).

Rape: Cases have been increasing since 1994/95, with a slight decline in 1998/99, but have steadily increased from 1999/2000 to the present (Figure 5). In a number of victim surveys conducted in South Africa since 1996, rape was described as one of the most widely feared crimes, second only to murder. ${ }^{4}$

It is widely acknowledged that crimes such as assault and rape are generally under-reported by the public, and sometimes under-recorded by the police. Various South African city victim surveys have shown that over $50 \%$ of these crime types go unreported. ${ }^{5}$ As odd as it may seem, the increase in reporting of these crimes to the police does not necessarily imply an increase in the occurrence of 
these crimes. The increase may be accounted for by changing public attitudes towards the police, a general improvement in the way police deal with victims of these crimes, and the impact of new laws like the Domestic Violence Act. The Act compels the police to record all reports of domestic violence, encouraging victims to come forward. This is important when taking into consideration the historic distrust between the police and public in this country.

The question whether the increases in attempted murder, assault, and rape are a reflection of real increases in the levels of these crimes, or the result of more victims reporting to the police, is important and needs to be answered. It has been suggested in the previous issue of the SA Crime Q uarterly (see Leggett, No 1, 2002) that many of the increases reflected in the SAPS crime statistics are probably the result of higher reporting rates. This issue can only be resolved by conducting regular national victim surveys that reveal more accurate levels of victimisation, and track reporting tendencies.

\section{Violent property crime}

Based on what has been recorded by the police, levels of aggravated robbery and common robbery are clearly on the increase. Aggravated robbery declined a little from 1994/95 to 1996/97, but increased from that year to 2001/02 (Figure 6). The rate of increase has however slowed down in the past year: between 2000/01 and 2001/02 robberies increased by only $3 \%$, compared to an increase of $13 \%$ between 1999/2000 and 2000/01. 'O ther' robberies have been increasing rapidly, with an average increase rate of about $15 \%$ per annum between 1994/95 and 2000/01. A sudden stabilisation was recorded in the past financial year (Figure 6).

The increase in violent property crime is one of the most worrying trends, impacting negatively on the country in various ways. Robbery tends to be indiscriminate and most of the time unpredictable, which makes any individual or institution with valuable and re-saleable assets, a potential victim. These factors, and the element of violence in this

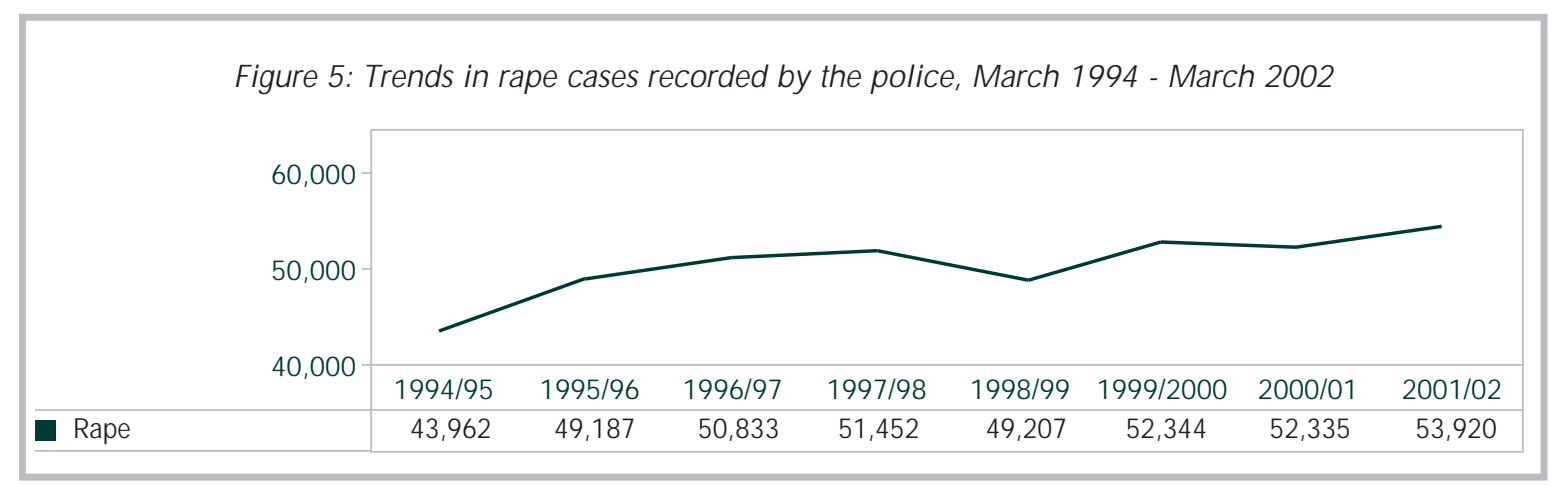

Figure 6: Trends for aggravated and 'other' robberies recorded by the police, March 1994 - March 2002

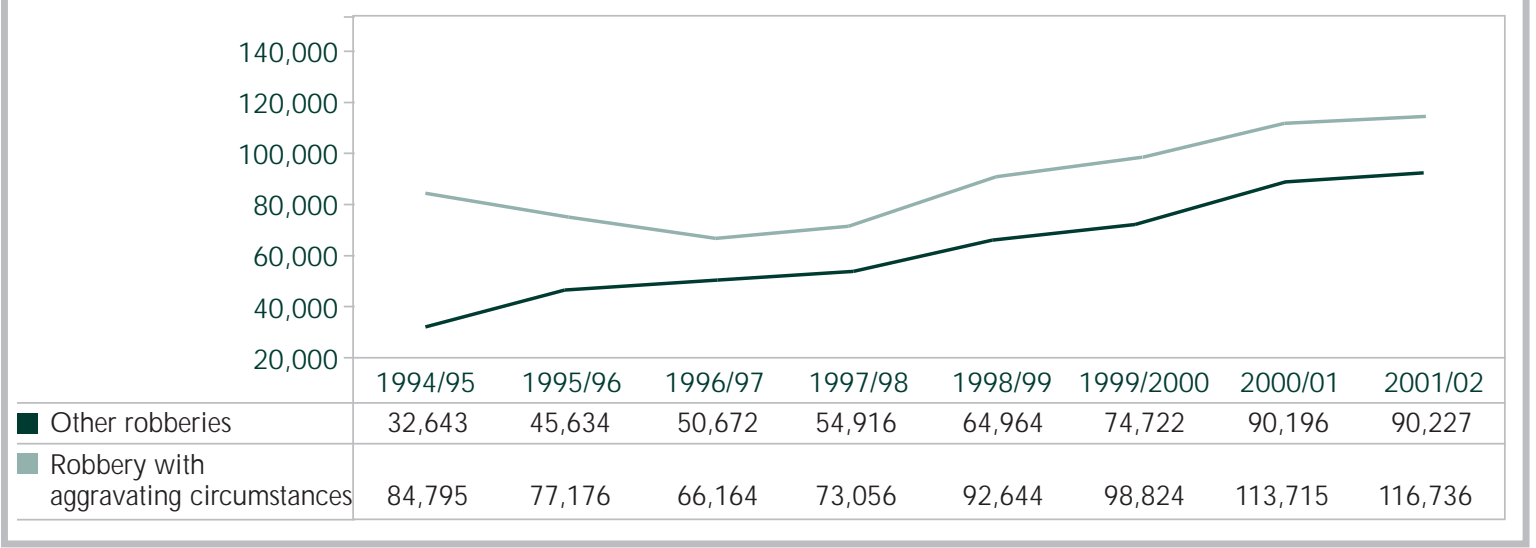


type of crime, contribute greatly to fear of crime in this country.

Taking into consideration the volume and the impact of these crimes, it is not surprising that government would attempt to convince the public that crime is stabilising. However, the trends from 1994/95 to 2001/02 discussed above question the 'stabilisation' analysis. With the exception of murder (which has decreased), other violent crimes are increasing rather than stabilising.

It is possible that law enforcement efforts in the past year have had a positive impact on crime levels. But debating the causes of trends that are based on recorded crime statistics - given their limited reflection of reality - is a rather pointless exercise. Attention should instead be focused on unravelling some of the mysteries behind the country's murder trends, and on understanding and targeting those risk factors that contribute to high levels of violence in society.

\section{Risk factors}

Victimisation and offending patterns are influenced by individual, social and environmental characteristics, commonly known as risk factors. Some of these factors, namely age, gender, race, the environment, alcohol, and firearms, are discussed below.

Studies have shown that, as far as age is concerned, the likelihood of violent involvement in crime increases sharply around age 15 and remains high until the mid-30s. However, when gender is also factored in, males between the ages of 15 and 25 years are more likely to be victims and perpetrators of violent crimes than are females.

According to the Department of Correctional Services 2001 annual report, a total of 26,682 prisoners were between the ages of 14 and 20 years (16\% of all prisoners). Considering that in the 1996 census $10 \%$ of the population was aged between 15 and 19 years, this suggests that this age group is over-represented in prison. Of all the juvenile prisoners, 26,204 were male $(98 \%)$ and 484 were female $(2 \%){ }^{6}$
In 1995/96 the per capita conviction rate of young males between 18 and 20 years guilty of serious violent crimes, was higher than that of older men, and women of all ages (see Nedbank ISS Crime Index 3(5) 1999). According to the $1999 \mathrm{~N}$ ational Injury M ortality Surveillance System, homicide deaths of both males and females increase sharply among 15 to 19 -year-olds, and peak among 25 to 29-year-olds. For males, homicide deaths begin to consistently decrease with age after the 30 to 34-year age bracket, whereas for females it remains high until age $40 .^{7}$

Police statistics and victim surveys conducted in South Africa also suggest a link between social depravation, race, and risk of victimisation. ${ }^{8}$ Victim surveys conducted from 1997 to 2000 show that the poor, the majority of whom are black and coloured and living in townships, are more at risk of being victims of interpersonal violent crimes as well as violent property crimes like robbery. By comparison, wealthy people living in the suburbs are most at risk of property crimes, in particular vehicle theft and burglary. ${ }^{9}$ In the $1999 \mathrm{~N}$ ational M ortality Surveillance System data, homicides of black and coloured people accounted for $93 \%$ of the 6,800 homicides reported. (This is higher than the $86 \%$ that these race groups make up of the total population recorded in the 1996 census.)

The risk of victimisation and offending in the case of violent crime is not only determined by who you are, but also where you are, when, and with whom. An analysis of violent crime trends from cases reported to the police and victim surveys shows a clear seasonal and weekly pattern in the occurrence of these crimes. The reporting and occurrence of interpersonal violent crimes tend to be high in holiday seasons, that is, December and April of each year (Figures 7 and 8). Most incidents happen on weekends, from Friday to Sunday.

Many of these incidents happen in private homes or places of entertainment, and victims frequently know their perpetrators by name or by sight. The 1999 N ational Injury M ortality Surveillance System shows that $58 \%$ of the 3,095 homicide cases reported were murdered at home or in a residential institution such as a hostel. According to the 
national Victims of Crime Survey conducted in 1998, more than two-thirds of sexual offence and assault victims knew the perpetrators - mostly by name (Figure 9).

At a community and neighbourhood level, violent crimes are influenced by factors such as overcrow ding, poor housing design, and a lack of infrastructure and development. Most residential areas inhabited by the poor, particularly the informal settlements, tend to be overcrowded with little living space for individuals and families. In most of these areas families share stands, and are without the basic amenities such as water taps, toilets, and, in some instances, electricity. These conditions are likely to create ongoing tensions between individuals and families, and may eventually lead to serious violent victimisation and offending.

Poor areas also tend to lack facilities such as streetlights, open routes and well-maintained public spaces, which are essential for both the police and the public in helping to prevent crime. ${ }^{10}$ In a crime prevention study conducted by the ISS for the Govan M beki municipality in Mpumalanga, residents in townships and informal settlements prioritised street lighting and bush clearing as key to their personal safety, while those in wealthier suburbs opted for burglar alarms and armed response services. ${ }^{11}$

The availability of firearms, alcohol and drugs increases the likelihood and severity of violent crimes. Studies conducted by the SAPS have revealed the linkages between alcohol abuse and the prevalence of certain types of violent crime such as assault. ${ }^{12}$ According to the $N$ ational Injury M ortality Surveillance System, $56 \%$ of 2,469 homicide victims sampled for blood alcohol level tested positive. ${ }^{13}$

Firearms are used in most violent crimes reported to the police. About 10,854 (49\%) of murders recorded by the police in 2000 were committed with a firearm. ${ }^{14}$ The trend for attempted murder is quite different: 21,967 out of 29,418 attempted murders $(75 \%)$ recorded by the police in 1998 involved the use of a firearm, ${ }^{15}$ as did $80 \%$ of 110,590 serious robberies recorded in $2000 .{ }^{16}$ South Africa has too many legal and illegal firearms in circulation. It is estimated that $3.76 \mathrm{~m}$ licensed firearms are in private use and that about half a million illegal guns are in circulation. It is likely that many illegal firearms were once legally owned guns; estimations are that about 82 privately owned firearms are lost or stolen every day. ${ }^{17}$ According to the SAPS, the police destroyed about 30,000 firearms between July and N ovember $2001 .{ }^{18}$ Given the above estimates of illegal firearms, this suggests that the police confiscation rate of illegal firearms is far too low.

\section{Who should be involved in preventing violent crime?}

Considering the nature and dynamics of violent crime, it is unfair and irresponsible to leave sole

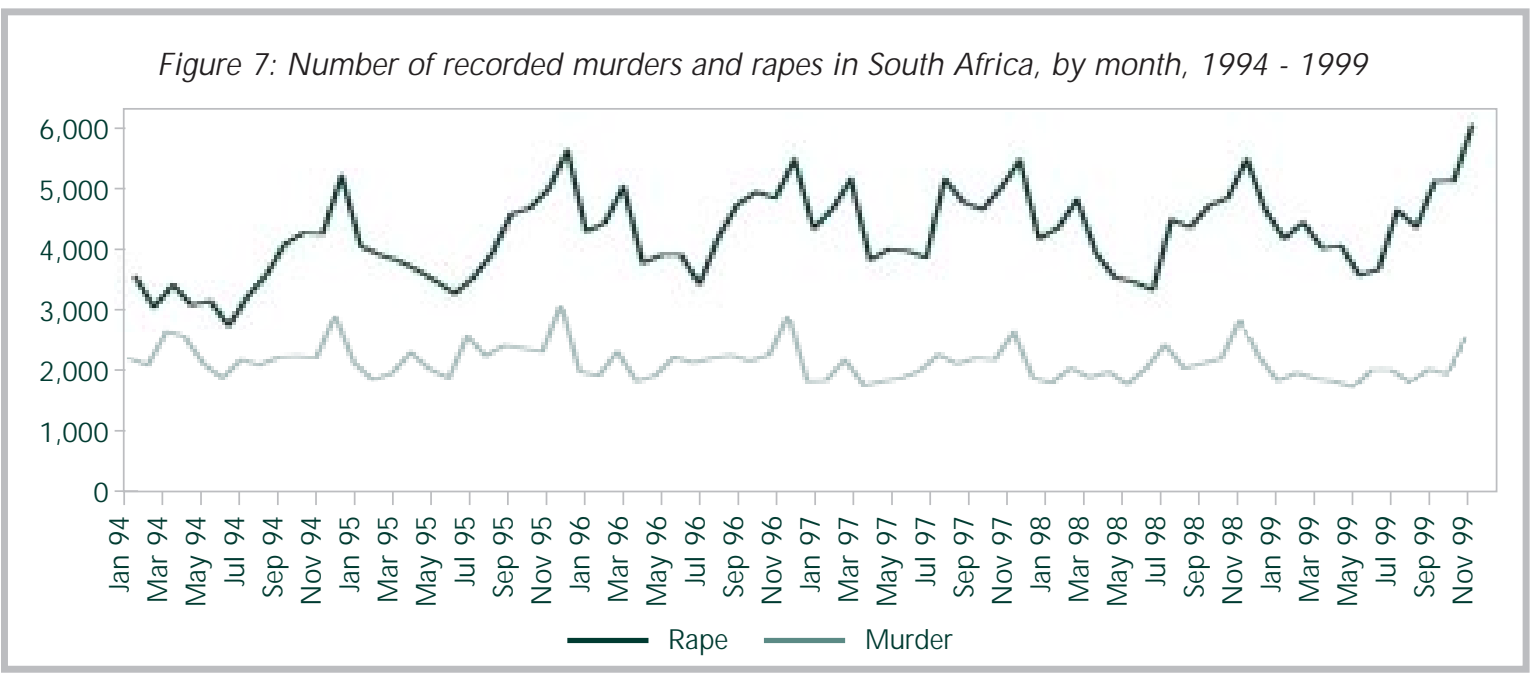


control and management of these crimes to the criminal justice system; the police, courts and prisons. The activities of the criminal justice system are reactive rather than preventative, the police usually respond to crimes during or after they have been committed. Similarly, the courts and prisons can only deal with offenders who have been arrested after the offence has been committed.

It follows that the control and management of crime and violent crime in particular cannot be the responsibility of the criminal justice system alone. The strategies required to deal with these crimes should involve those responsible for welfare and social development, law enforcement and environmental modification. This implies a crucial role for other government departments, in particular, the departments of social development, education, and local government.

The successful reduction of these crimes will require the modification and implementation of existing policies. The Department of Social D evelopment should prioritise the implementation of creative family and community development programmes. The Department of Education should ensure the effective early childhood and adolescent development of South African children. Local governments should make sure that essential basic services are delivered to communities. These efforts

Figure 8: N umber of recorded serious assaults in South Africa, by month, 1994 - 1999

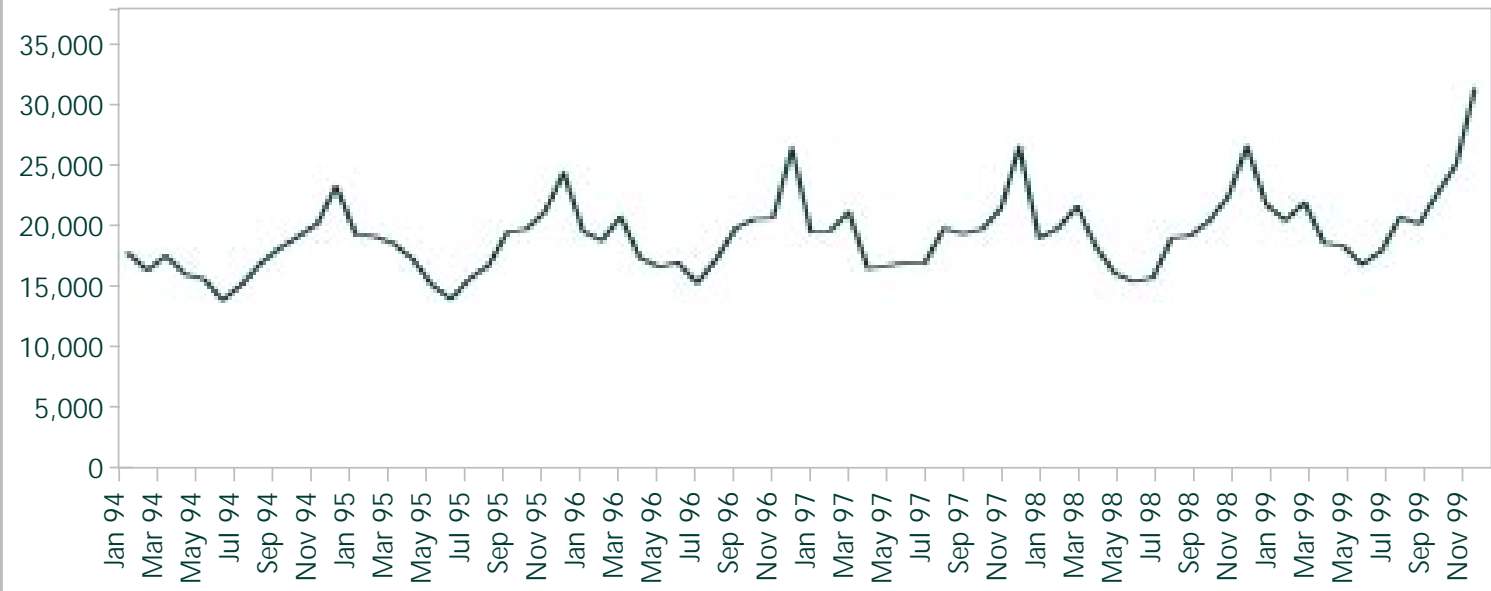

Figure 9: \% of victims who knew the offender, ISS city victim surveys and national victim survey, 1998

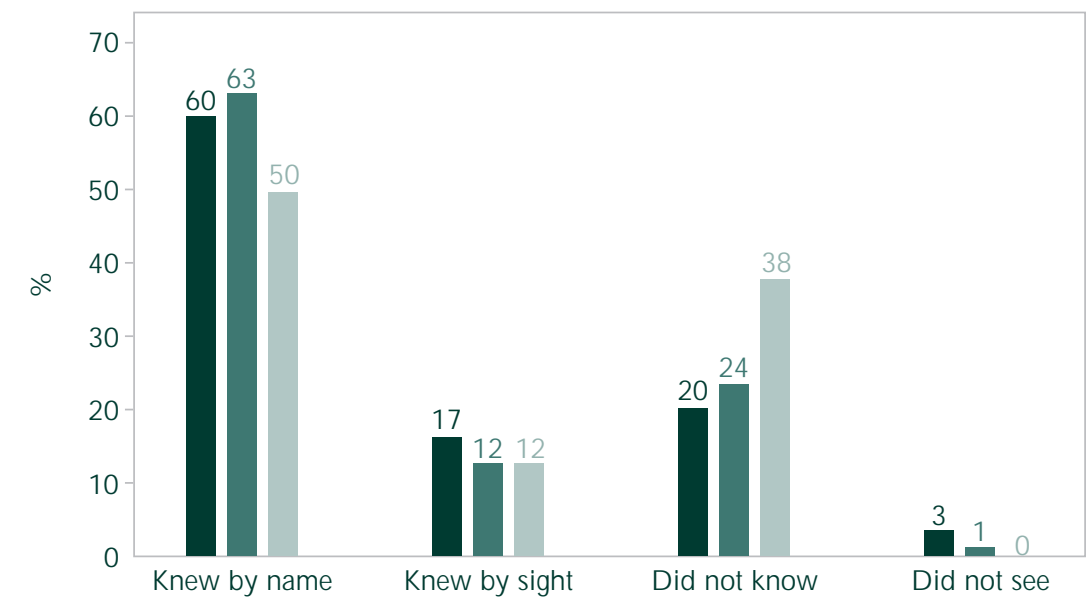

Assault

- Sexual offence

Murder 
should increase public support and participation - a crucial ingredient for preventing violent crime.

The key question remains; who should be responsible for driving the effort to prevent violent crime? O ver the years there has been a general acceptance of the need to involve the departments mentioned above. W hether the Department of Safety and Security should be the leading crime prevention agency as outlined in policy and practice, is however debatable. This certainly does not mean the police should in any way be absolved of their role in policing violent crimes. $\mathrm{O}$ the contrary, laws such as the Domestic Violence Act obligate the police to perform a wide range of essential functions when victims report domestic violence. (And if studies of the quality of police service to survivors of abuse are anything to go by, there is plenty of work required in this regard. ${ }^{19}$ ) Rather, a debate is needed about whether the police, given that they can (and should) only play a secondary role in prevention, ought to have the primary role in leading crime prevention policy and strategy.

\section{Endnotes}

1 Annual Report of the National Commissioner of South African Police Service, 1 April 2001 to $31 \mathrm{March}$ 2002, Pretoria, 2002.

2 Statistics South Africa, Victims of crime survey 1998, statistical release P0341, Pretoria, 1998

3 Home O ffice, Fighting Violent Crime Together: An action plan, UK, 2001. www.homeoffice.gov.uk/actionplan/violentcrime.htm

4 S M asuku and A Louw, Towards a Crime Reduction Strategy in Highveld East Municipality, U npublished ISS report, 2001.

5 T Leggett, Improved Crime Reporting: Is South Africa's crime wave a statistical illusion? South African Crime Q uarterly 1 (1), July 2002, pp 7-9.

6 Annual Report, Department of Correctional Services, 1 January 2000 to 31 March 2001, Pretoria 2002.

7 National Injury Mortality Surveillance System, First Annual Report of the National Injury M ortality Surveillance System: A Profile of Injuries in South Africa, 1999

8 See A Louw and M Shaw, Stolen opportunities: the impact of crime on South Africa's poor, ISS Monograph Series, No 14, 1997.

9 M Schonteich and A Louw, Crime in South Africa: A country and cities profile, ISS Paper 49, April 2001.

10 A Louw and M Shaw, op cit.

11 S Masuku and A Louw, op cit.
12 SAPS Crime Information Analysis Centre.

13 N ational Injury M ortality Surveillance System, 1999, op cit.

14 Senior Superintendent A Lesch, Firearms control act, Act 60/2000, Presentation at the Technicon South Africa Seminar, 31 July 2002.

15 Senior Superintendent A Lesch, op cit. The total number of attempted murders in 1998 was drawn from the Crime Information Analysis Centre's website 'Provincial crime specific statistics 1994 to 2000', <http://www.saps.org.za/8_crimeinfo/bulletin/942000/i ndex.htm>

16 S M eek, The impact of firearms in South Africa, Presentation to Parliament Safety and Security Portfolio Committee, 14 August 2002.

17 Ibid.

18 Annual Report of the National Commissioner of South African Police Service, op cit.

19 S Rasool et el, Violence Against Women: a national study, Institute for Security Studies, Pretoria, 2002 (forthcoming). 